\title{
Inflammatory bowel disease: The pathology of recurrence
}

\author{
JAMES K KELLY, MB, FRCPATH, FRCPC
}

JK KELLY. Inflammatory bowel disease: The pathology of recurrence. Can J Gastroenterol $1993 ; 7(2): 219-222$. Current knowledge of the pathology of recurrent Crohn's disease is derived from study of endoscopic biopsies of recurrent lesions and surgical re-excision specimens. The main site of recurrence is the neoterminal ileum. The first lesions identified endoscopically are aphthous ulcers. Later lesions are serpiginous ulcers separating nodular mucosal remnants. Finally stenosis of the neoterminal ileum or anastomosis develops. Even though the terminal ileum looks normal endoscopically there may be focal inflammation on biopsy indicating that inflammation precedes ulceration. Granulomas are also early lesions. Mucosal regeneration, gastric metaplasia, submucosal lymphoid follicular aggregates and transmural inflammation follow ulceration in time. Strictures and sinuses are late complications. In re-excision specimens sinuses and fistulae may arise at the anastomosis. The absence of disease at resection margins does not prevent recurrence and there is no indication for frozen section of the margins at surgery. Disease at a resection margin does not affect postoperative anastomotic integrity. These facts emphasize that the principle in the surgical management of Crohn's disease should be conservation of tissue. Crohn's disease confined to the appendix is not followed by development of Crohn's disease of the bowel in the vast majority of instances. Ulcerative colitis does not recur following colectomy and ileostomy. Chronic ileal pouchitis refractory to antibiotic therapy may have a histological appearance resembling either ulcerative colitis or Crohn's disease. The former may represent a recurrence of ulcerative colitis and the latter a misdiagnosis of Crohn's disease, but the biology and natural history of the various forms of pouchitis are not yet elucidated.

Key Words: Crohn's disease, Pouchitis, Recurrence, Ulcerative colitis

\section{Maladie intestinale inflammatoire : pathologie de la récurrence}

RÉSUMÉ: Les connaissance actuelles sur la pathologie de la maladie de Crohn récurrente dérivent de l'étude de biopsies endoscopiques des lésions récurrentes et des spécimens chirurgicaux de réexcision. Le principal foyer de récurrence est l'iléon néoterminal. Les premières lésions identifiées par endoscopie sont les

University of Calgary and Foothills Hospital, Calgary, Alberta

Correspondence and reprints: Dr JK Kelly, Department of Pathology, Foothills Hospital, Calgary, Alberta T2N 2T9. Telephone (403) 670-4753, Fax (403) 670-4748
ROHN'S DISEASE IS CHARAC
terized by recurrence after surgery whereas ulcerative colitis is cured by resection. Whether chronic pouchitis refractory to antibiotics represents a form of recurrent ulcerative colitis is uncertain. Early Crohn's disease at first onset is clinically silent and is not amenable to detection or pathological study. However, following curative surgery, the pathology of recurrent Crohn's disease can be investigated either by serial endoscopy and biopsy (1-3) or by studying surgical specimens from re-excisions (4). Current knowledge about the natural history of the anatomic lesions of Crohn's disease is based mainly on study of the lesions of recurrent Crohn's disease following primary excision.

\section{NATURAL HISTORY}

Rutgeerts et al (1) studied the natural history of recurrent Crohn's disease at the ileocolic anastomosis by performing endoscopy on 114 out of 165 patients in whom a curative resection had been carried out up to 10 years earlier. Twenty-nine patients were endoscoped at up to one year after resection, 24 between one and three years postoperatively and 61 patients between three and 10 years postoperatively. The proportion of patients 
ulcères aphteux. Les lésions qui suivent sont les ulcères serpigineux qui séparent les résidus de muqueuses nodulaires. Finalement, la sténose de l'iléon néoterminal ou de l'anastomose se développe. Même si l'iléon terminal semble normal à l'endoscopie, il peut y avoir inflammation localisée à la biopsie indicatrice de l'inflammation qui précède l'ulcération. Les granulomes sont également des lésions précoces. La régénération de la muqueuse, la métaplasie gastrique, les agrégats folliculaires lymphoïdes sous-muqueux et l'inflammation transmurale suivent éventuellement l'ulcération. Les rétrécissements et les sinus sont des complications tardives. Les spécimens de réexcision s'accompagnent de sinus et de fistules parfois à l'anastomose. L'absence de lésions aux marges de la résection n'empêche pas la récurrence et il y a indication pour procéder une section congelée des marges au moment de la chirurgie. Les lésions au niveau des marges de la résection n'affectent pas l'intégrité post-opératoire de l'anastomose. Ces faits soulignent que le principe du traitement chirurgical de la maladie de Crohn vise la conservation des tissus. La maladie de Crohn confinée à l'appendice ne se développe pas vers l'intestin dans la grande majorité des cas. La colite ulcéreuse ne récidive pas suite à la colectomie et à l'iléostomie. L'iléite chronique réfractaire à l'antibiothérapie peut ressembler au plan histologique à la colite ulcéreuse ou à la maladie de Crohn. La première représentera une récurrence de la colite ulcéreuse et la seconde, une maladie de Crohn mal diagnostiquée, mais l'étiologie et l'histoire naturelle des diverses formes d'inflammation de la muqueuse du réservoir demeurent inconnues.

showing recurrence was $72 \%$ at less than one year, $79 \%$ at one to three years, and $77 \%$ at three to 10 years. In patients with recurrence less than one year postoperatively the signs of recurrence were aphthous ulcers in threequarters of patients, and mucosal nodules separated by large or serpiginous ulcers in the remaining quarter. Patients between one and three years postoperatively showed mainly mucosal nodules and serpiginous ulcers but some had aphthous ulcers alone and a few had already advanced to stenosis. Almost half of all patients more than three years after previous excision $(60 \%$ of those with recurrence) showed stenosis of the neoterminal ileum, and the others showed mainly nodules and larger ulcers but only a few showed aphthous ulcers. In the patients who had endoscopic abnormalities, the main biopsy findings were blunting and irregularity of the villi, severe focal nonspecific inflammation, and ulceration. The neoterminal ileum was normal on endoscopy in 27 of the 114 patients. Biopsies of neoterminal ileum from these 27 patients were normal in 19 patients but showed focal inflammation in eight patients $(30 \%)$. This finding is evidence that mucosal inflammation precedes ulceration and agrees with the evidence of focal inflammation in the grossly normal rectum identified by the magnifying endoscope (5) or in random biopsies (6). In the patients in whom surgery had been performed less than one year before the endoscopic evaluation, $32 \%$ of biopsy specimens were normal, ulcerations were seen in only $8 \%$ of specimens and inflammation in the remaining $60 \%$. Eosinophil leukocytes were the main cells in the inflammatory infiltrate in $25 \%$ of these early recurrent lesions.

This study clearly showed that the neoterminal ileum is the main location of recurrent disease and that the sequence of lesions in the mucosa includes initial inflammation progressing to small ulcers, large ulcers with nodular mucosa, and ultimately to stricture (1).

In a later paper, Rutgeerts et al (2) reported 22 patients who were subjected to curative ileal resection and ileocolic anastomosis. Each patient had careful examination of the segment to be used as neoterminal ileum at the time of making the anastomosis. Biopsies were taken from the neoterminal ileum at $4 \mathrm{~cm}$ proximal to the anastomosis. When endoscopy was performed six months after surgery, 21 of 22 were found to have ileitis involving a segment ranging from 4 to $30 \mathrm{~cm}$ in length, and 20 of 22 had unequivocal microscopic lesions on biopsies. This study provides strong evidence that early recurrent lesions in the neoterminal ileum do not originate from microscopic inflammation that is already present at the time of surgery. In a subsequent study none of five patients who had diversion of the fecal stream proximal to the neoterminal ileum showed inflammatory changes characteristic of Crohn's disease at six months. However, when continuity of the fecal stream was restored, lesions developed in the neoterminal ileum in all patients (3). These findings strongly support the view that recurrence of Crohn's disease in the neoterminal ileum is dependent on the fecal stream.

\section{PATHOLOGICAL FEATURES}

Another approach to the pathology of recurrent Crohn's disease was a study of 63 re-excision specimens from patients who had no evidence of residual disease at the time of surgery (4). The majority of the specimens were revisions of ileocolic anastomosis and the recurrent disease was present in the ileum alone in 42 cases, in both ileum and large bowel in 20 cases, and in the colon alone in one case. The presence or absence of nine pathological features characteristic of Crohn's disease was related to time from previous resection. The features studied were small ulcers, granulomas, regeneration, metaplasia, submucosal lymphoid aggregates, transmural inflammation, large ulcers, sinuses and strictures. The earliest developing lesions were identified by first quartile times, the first quartile being the median of the first half of the specimens in each group (Table 1). Small ulcers and granulomas had the lowest first quartile times and were present without other features in nine specimens. Regeneration, metaplasia, submucosal lymphoid follicular inflammation and transmural inflammation followed small ulcers in time, and, together with large ulcers, preceded sinuses and stric. tures. No attempt was made to study preulcerative focal inflammatory lesions other than granulomas because accurate distinction of small ulcers 
TABLE 1

First quartile and median times in months for lesions of recurrent Crohn's disease

\begin{tabular}{lcc}
\hline & Quartile & Median \\
\hline Small ulcers & 8.5 & 34 \\
Granulomas & 8.5 & 40 \\
Regeneration & 17 & 40 \\
Metaplasia & 24.5 & 41 \\
Submucosal follicles & 24 & 42 \\
Transmural inflammation & 24 & 45 \\
Large ulcers & 34 & 50 \\
Sinuses & 45 & 82 \\
Strictures & 50 & 84 \\
\hline
\end{tabular}

from foci of inflammation alone would have required serial sectioning.

These studies confirmed the radiological, endoscopical and pathological studies that had previously identified small ulcers as early lesions of Crohn's disease $(7,8)$. The time sequence indicated that regeneration, metaplasia, submucosal lymphoid follicles and transmural inflammation follow small ulcers in time and are likely a consequence of ulceration and mucosal inflammation. The submucosal lymphoid follicular aggregates, which are said to be the most consistent diagnostic feature of Crohn's disease (9), do not precede mucosal ulceration but rather follow it. Large ulcers precede sinuses and strictures in time, but all three are intimately related suggesting that the fibromuscular thickening of muscularis mucosae that leads to sinuses and strictures is a consequence of ulceration (10). Thus ulceration is of primary significance in the morphological progression of Crohn's disease to stricturing, symptomatic and complicated disease (4). Cases of gastric metaplasia were a subset of cases with regeneration, indicating that metaplasia is one manifestation of the regenerative process in the

\section{REFERENCES}

1. Rutgeerts P, Geboes K, Vantrappen G, Kerremans R, Coenegrachts JL, Coremans G. Natural history of recurrent Crohn's disease at the ileocolonic anastomosis after curative surgery. Gut 1984;25:665-72.

2. Rutgeerts P, Geboes K, Vantrappen G, Beyls J, Kerremans R, Hiele M. small intestine, just as intestinal metaplasia is a feature of mucosal regeneration in the stomach (11).

Granulomas: In addition to being early lesions (4), granulomas are associated with a short clinical history $(12,13)$, younger age $(13,14)$, non-HLA-B8 phenotype (15), more extensive disease and greater degree of peripheral lymnumber per unit area from cecum to anus in colonic Crohn's disease (12, 13). Granulomas do not affect postoperative recurrence rates (17).

Resection margins: Many papers show that the absence of disease at resection margins does not prevent clinical recurrence (18-20) but, as might be expected, earlier recurrence is more likely if the resection margin is diseased $(21,22)$. This may be partly a result of more severe long segment disease. Since Crohn's disease recurs whether resection margins are free of disease or not $(1-4)$, there is no indication for assessment of the margins by frozen section $(18-20)$, although minimal clearance of advanced ulcerative or stenosing disease visible to the naked eye is obviously desirable, particularly in short segment disease. Second, disease at the margin does not, in general, affect postoperative anastomotic in-

Predictability of the postoperative course of Crohn's disease. Gastroenterology 1990;99:956-63.

3. Rutgeerts P, Geboes K, Peeters M, et al. Effect of faecal stream diversion on recurrence of Crohn's disease in the neoterminal ileum. Lancet 1991;338:771-4.

4. Kelly JK, Sutherland LR. The phopenia (16). Granulomas increase in tegrity (23) and strictureplasty is usually successful. However, in re-excision specimens fistulae most often arise at the anastomosis (24) rather than at the usual site of origin at the proximal ends of strictures (10). Fistulae in re-excision specimens often penetrate to the skin (24).

Primary Crohn's disease of the appendix: Transmural appendicitis with ulceration and granulomas in the absence of ileitis is unlikely to be Crohn's disease, because the vast majority of such patients never develop Crohn's disease of the bowel (25-27). Indeed, the appendix is rarely involved in Crohn's disease and perhaps this reflects its position outside the direct fecal stream, since lesions may be related to the fecal stream (3).

Pouchitis: Pouchitis is a clinical syndrome of pouch diarrhea which may be blood-stained and may be associated with systemic symptoms and extraintestinal manifestations. The incidence of pouchitis is between $16 \%$ and $30 \%$ of patients with pouches. The majority of cases respond to antibiotic treatment with metronidazole or combinations of metronidazole with other antibiotics (28). A small proportion of cases are refractory to antibiotics. These cases appear to fit into two groups histologically. The majority display histology similar to idiopathic ulcerative colitis and may be associated with evidence of metaplasia to a mucosa of colonic type. The others have Crohn's disease-like histology and may be cases where Crohn's disease was misdiagnosed. Control pouches look normal histologically but may show a mild neutrophil infiltrate in the crests of the villi. Acute antibiotic-responsive pouchitis is characterized by heavy neutrophil infiltration with villous atrophy and crypt hyperplasia.

chronological sequence in the pathology of Crohn's disease.

J Clin Gastroenterol 1988;10:28-33.

5. Makiyama K, Bennett MK, Jewell DP.

Endoscopic appearances of the rectal mucosa of patients with Crohn's disease visualised with a magnifying colonoscope. Gut 1984;25:337-40.

6. Korelitz Bl, Sommers SC. Rectal 
biopsies in patient with Crohn's disease. Normal mucosa on sigmoidoscopic examination. JAMA 1977;237:2742-4.

7. Rickert RR, Carter HW. The 'early' ulcerative lesions of Crohn's disease: Correlative light and scanning electron microscopic studies. Clin Gastroenterol 1980;2:11-9.

8. Rappaport H, Burgoyne FH, Smetana HF. The pathology of regional enteritis. Military Surg 1951;109:463-502.

9. Cook MG, Dixon MF. An analysis of the reliability of detection and diagnostic value of various pathological features in Crohn's disease and ulcerative colitis. Gut 1973;14:255-62.

10. Kelly JK, Siu TO. The strictures sinuses and fissures of Crohn's disease. J Clin Gastroenterol 1986;8:594-9.

11. Makawa K, Nakamura T, Nakano G, Nagamachi Y. Histopathogenesis of intestinal metaplasia in ulcerated stomachs. J Clin Pathol 1987;40:13-8.

12. Chambers TJ, Morson BC. The granuloma in Crohn's disease. Gut 1979;20:269-74.

13. Schmitz-Moormann P, Pittner PM, Malchow H, Brandes JW. The granuloma in Crohn's disease. A bioptical study. Path Res Pract 1984; 178:467-76.

14. Assarsson N, Raf L. Incidence of granulomas in Crohn's disease. Acta Clin Scand 1974;140:249-51.

15. Holdstock G, Macpherson B, Beeken WL. HLAB8 and granuloma formation in Crohn's disease. Gut 1982;23:600-2.

16. Heimann TM, Miller F, Martinelli G, Szporn A, Greenstein AJ, Aufses AH. Correlation of presence of granulomas with clinical and immunologic variables in Crohn's disease. Arch Surg 1988;123:46-8.

17. Wolfson DM Sachag DB, Cotten A, et al. Granulomas do not affect postoperative recurrence rates in Crohn's disease. Gastroenterology 1982;83:405-9.

18. Hamilton SR, Reese J, Pennington L, et al. The role of resection margin frozen section in the surgical management of Crohn's disease. Surg Gynecol Obstet 1985;160:57-62.

19. Heuman R, Boeryd B, Bolm T, Sjodahl R. The influence of disease at the margin of resection on the outcome of Crohn's disease. Br J Surg 1983;70:519-21.

20. Kotanagi $\mathrm{H}$, Kramer K, Fazio VW, Petras RE. Do microscopic abnormalities at resection margins correlate with increased anastomotic recurrence in Crohn's disease? Retrospective analysis of 100 cases. Dis Colon Rectum 1991;34:909-16.
21. Lindhagen T, Ekelund G, Leandoer L, Hildell J, Lindstrom C, Wenckert A. Recurrence rate after treatment of Crohn's disease. Scand J Gastroenterol 1983;18:1037-44.

22. Wolff BG, Beart RW, Frydenberg HB, Weiland LH, Agrez MV, Ilstrup DM. The importance of disease-free margins in resections for Crohn's disease. Dis Colon Rectum 1988;26:239-43.

23. Wong J, Preshaw RM, Reid DF, Kelly JK. Resection margin involvement with Crohn's disease and postoperative anastomotic integrity. Can J Gastroenterol 1989;3:95-7.

24. Kelly JK, Preshaw RM. Origin of fistulas in Crohn's disease. J Clin Gastroenterol 1989;11:193-6.

25. Wettergren A, Munkholm P, Larsen LG, et al. Granulomas of the appendix: Is it Crohn's disease? Scand J Gastroenterol 1991;26:961-4.

26. Lindhagen T, Ekelund G, Leandoer L, Hildell J, Lindstrom C, Wenckert A. Crohn's disease confined to the appendix. Dis Colon Rectum 1982;25:805-8.

27. Yang SS, Gibson P, McCaughey RS, Arcari FA, Bernstein J. Primary Crohn's disease of the appendix. Report of 14 cases and review of the literature. Ann Surg 1979;189:334-9.

28. Shepherd NA. The pelvic ileal reservoir: pathology and pouchitis, Neth J Med 1990;37(Suppl 1):S57-64. 


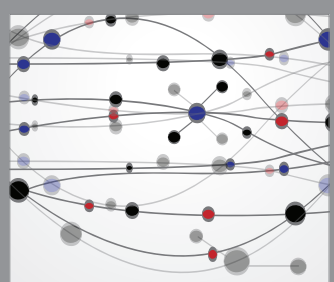

The Scientific World Journal
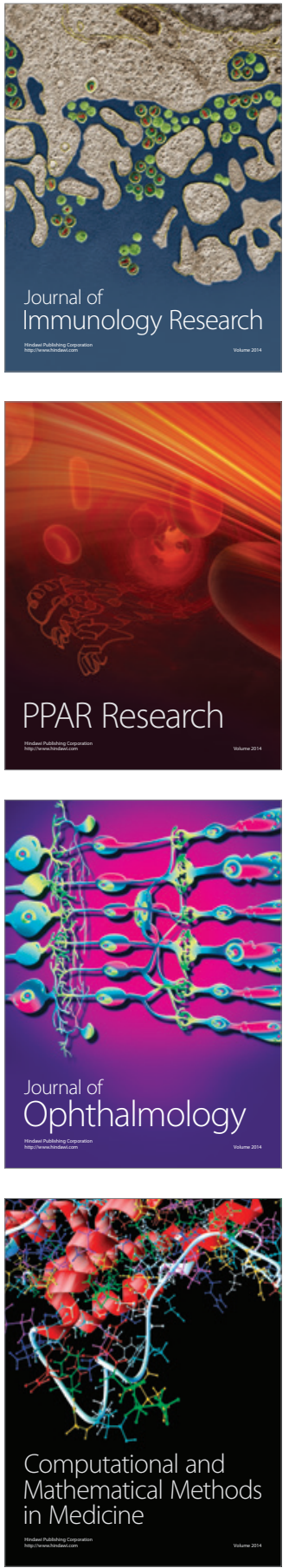

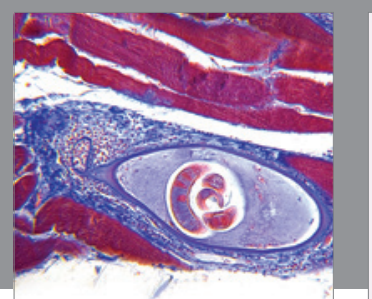

Gastroenterology Research and Practice

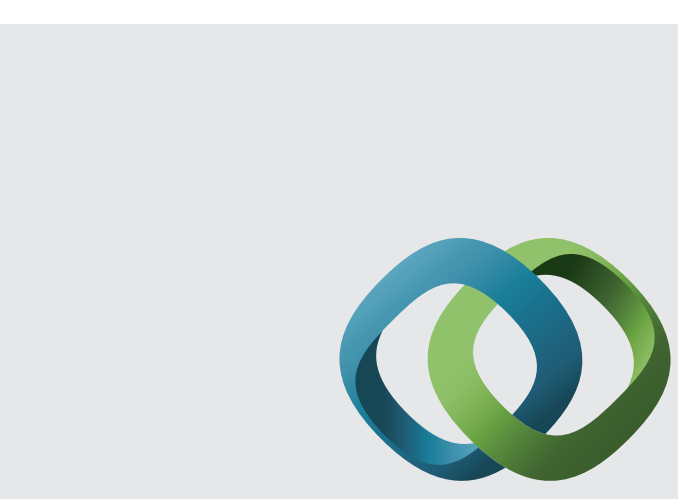

\section{Hindawi}

Submit your manuscripts at

http://www.hindawi.com
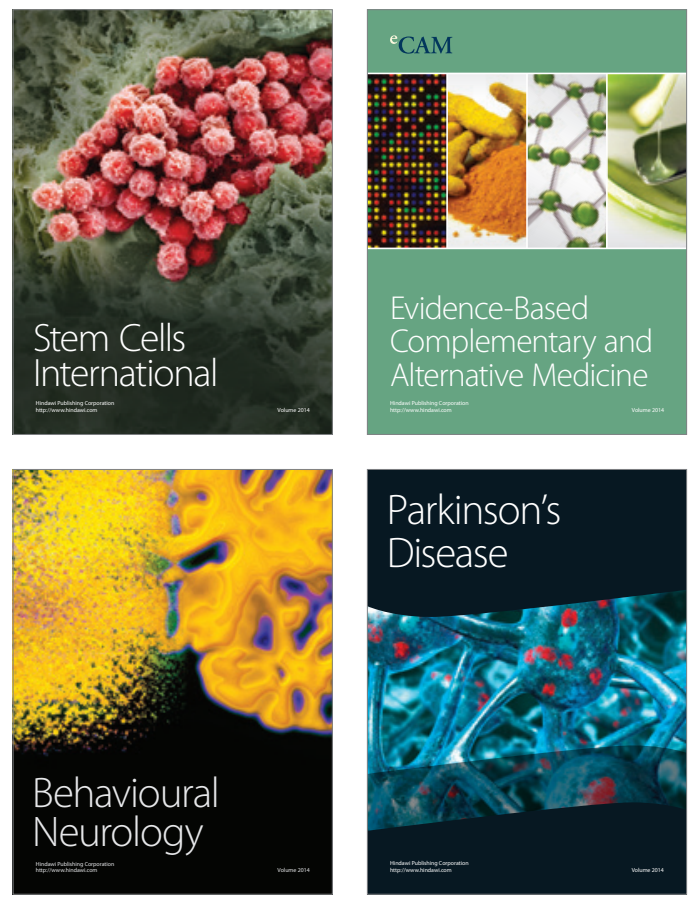
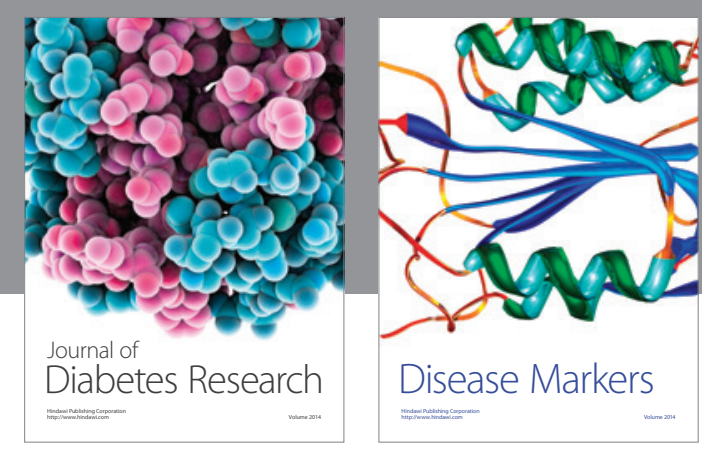

Disease Markers
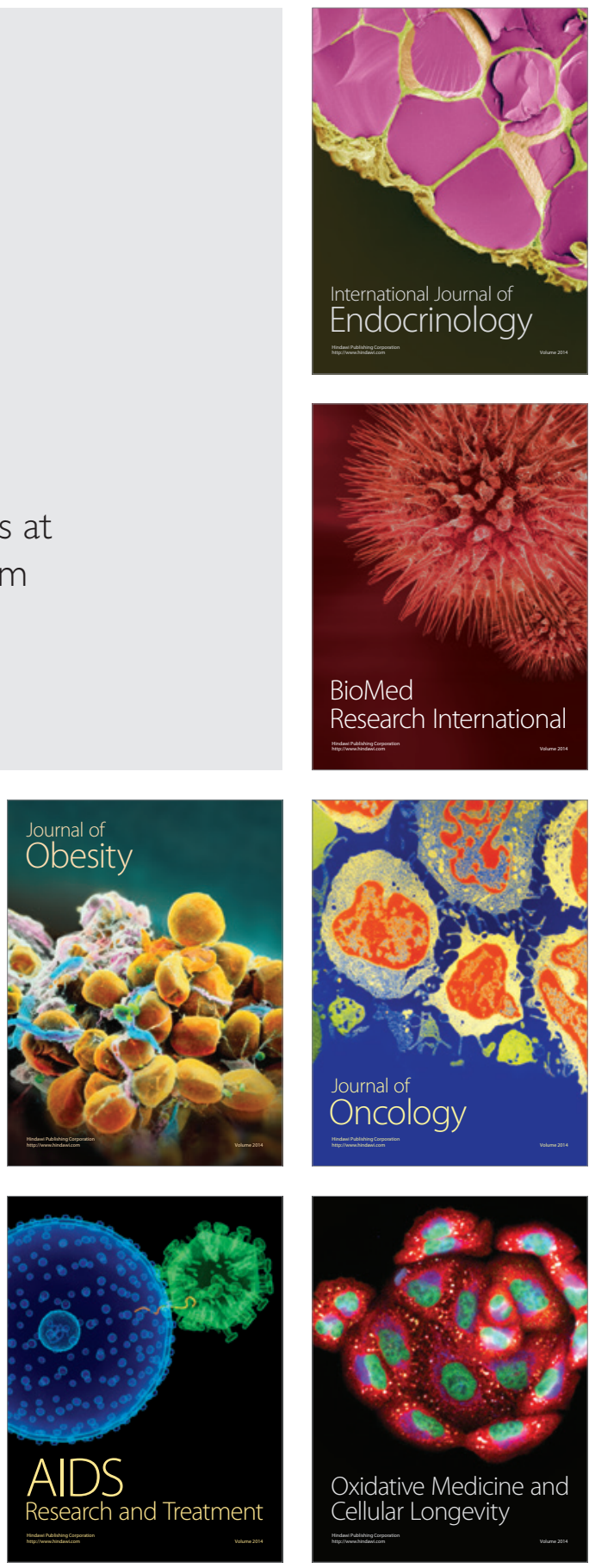